\title{
The Morbidity Profile of the Elderly in Arehalli Village of Hassan District
}

\author{
*Shivakumar S. Madagundi, Dr. (Smt) Jayashree \\ Research Scholar,Chairperson, Department of Sociology,Karnatak University, Dharwad-03
}

\begin{abstract}
Morbidity among elderly people has an important influence on their physical functioning and psychological well being. Morbidity Profile and its determinants have lot of implications of elderly people's life. Morbidity is the study of the frequency of disease, illness, sickness of ill-health in a population.

Morbidity data are usually classified according to the international classification of diseases, and are broken down according to such variables as age, sex place of residence, and socio-economic characteristics. Morbidity is the extent of illness (disease) injury, or disability in a defined population. Particularly in circumstances of low mortality, such as exist now in the industrialized nations, morbidity data give a fuller description of the physical well being of a population than do mortality data. Mortality data do not reflect the level of nonfatal illness or impairments, or mental illness (John A. Ross, 1982).

Objective of the Elderly:

- To understand the Socio-Economic and Educational family background of rural elderly.

- To examine the status and morbidity profile of rural elderly.

- To know the health problems faced by the Aged.

Hypothesis:

In the light of the above objectives the following hypotheses have been framed, and the same will be tested on the basis of the primary data collected by researcher:

- Most elderly people have multiple health problems.

- Morbidity Profile depends on income, awareness, health facilities and life style of the respondents.
\end{abstract}

\section{Introduction:}

Morbidity among elderly people has an important influence on their physical functioning and psychological well being. Morbidity Profile and its determinants have lot of implications of elderly people's life. Morbidity is the study of the frequency of disease, illness, sickness of ill-health in a population.

Morbidity data are usually classified according to the international classification of diseases, and are broken down according to such variables as age, sex place of residence, and socio-economic characteristics. Morbidity is the extent of illness (disease) injury, or disability in a defined population. Particularly in circumstances of low mortality, such as exist now in the industrialized nations, morbidity data give a fuller description of the physical well being of a population than do mortality data. Mortality data do not reflect the level of nonfatal illness or impairments, or mental illness (John A. Ross, 1982).

According to the 2001 Census, India is home to more than 76 million people aged 60 years and over. This age group, currently $7.4 \%$ of the population, is expected to grow dramatically in the coming decades. This aging and also the demand for specialist services should be more evident in regions with favorable health indicators (Sathyanarayana and Shaji, 2007).

Presently, limited studies have been carried out also due to the absence of a nationwide registry of older people comprehensive community based data on Morbidity and Disability is unavailable (Dhar, 2005). There is a strong need for making available information on the health needs of this rapidly graying population, especially those disabled, as this would be one of the most important challenges. It is in this context that this study attempts to explore the morbidity profile of the aged and some important variables affecting the same among elderly people residing in Arehalli Village.

Morbidity has been defined as "any departure, subjective or objective, from a state of physiological well being. The term is used equivalent to such terms as sickness, illness disability WHO Expert Committee on Health Statistics noted on its $6^{\text {th }}$ Report that Morbidity could be measured in terms of three units. (i) Person who were ill, (ii) the illnesses (provides of spells of illness) that these persons experienced and (iii) the duration (days, weeks etc) of these illnesses.

The elderly population has special health problems that are basically different from those of adult or young. Most diseases in aged are chronic nature; cardiovascular, arthritis stroke, cataract, deafness, cancer, chronic infections etc., disease process are usually multiple. 
This study explores the Morbidity Profile among 100 elderly of the respondents in Arehalli Village through interview technique. Divided into three age groups 60-69, 70-79 and 80+.

\section{Objectives of the Elderly:} objectives;

The major aim of this paper is to study of Morbidity profile of Elderly with the following three

- To understand the Socio-Economic and Educational family background of rural elderly.

- To examine the status and morbidity profile of rural elderly.

- To know the health problems faced by the Aged.

\section{Hypothesis:}

In the light of the above objectives the following hypotheses have been framed, and the same will be tested on the basis of the primary data collected by researcher:

- Most elderly people have multiple health problems.

- Morbidity Profile depends on income, awareness, health facilities and life style of the respondents.

\section{Area of Study:}

Arehalli is a Village in the Southern state of Karnataka. It is located in the Belur Taluk of Hassan District in Karnataka. As of 2001 India Census Arehalli had a total population of 6339 with 3141 Males and 3198 Females.

\section{The Sample:}

The study was carried out on a sample of 100 Elderly aged 60-69, 70-79 and 80+ were selected based on the simple random sampling. A total sample 100 respondents consisting 65 females and 35 males were Interviewed using Questionnaires.

\section{Methodology:}

This study explores the Morbidity Profile of the Elderly in Arehalli Village of Hassan District. Among 100 respondents of elderly 60 years and above in Arehalli Village. Through the interview technique, from January 2012 to June 2012. For the study preparation of this study we used a primary data collected through interviews, and the required secondary data for the study are collected from the books, journals, articles, reports, previously conducted studies and news papers.

\section{Review Of Literature:}

There are host of studies carried out in the field of ageing and morbidity profile of the aged and its associated problems E.g., Studies by (Birren 1964, Kumudini Dandekar 1966, S. Irudaya Rajan, V.S. Mishra and P. Sankara Sarma 1999, and Arvind K. Joshi 2006 etc.,)

Joshi K. et al (2003) Study concentrates on "Morbidity Profile and its relationship with disability and psychological distress among elderly in Northern India". Morbidity Profile of rural elderly people were distressed Physically, Psychologically and both. The most prevalent morbidity was anemia, followed by the dental problems, hypertension, chronic obstructive airway disease, Cataract and Osteoarthritis. Another important study conducted by Vinod Kumar (2005) age related disorders include life threatening diseases such as heart disease, stroke, cancer, diabetes, and infections, as well as certain chronic disabling conditions affecting vision, mobility hearing, and cognition.

Lena A, Ashok K, Padma M, Kamath V. Kamath A (2003) Conducted study in "Health and Social Problems of the Elderly: A Cross Sectional Study in Udupi Taluk, of Karnataka". The Health Problems of the Elderly all the respondents had health problems, the most common being hypertension, osteoarthritis, diabetes, or bronchial asthma, others included cataract, anemia, and skin problems.

K. Vijayakumar et al (1992) conducted a survey in Thiruvananthapuram city, Kerala to assess the health and functional status of the elderly Out of the 658 elderly covered 20.15 of males and $68.1 \%$ of females were widowed. The women were found to be poorer suffering a lot having more morbidity than the men, in spite of their greater life expectancy. 
TABLES:

Table No. 01

Age and Sex Profile of the Respondents

\begin{tabular}{|c|lr|c|c|c|c|}
\hline \multirow{2}{*}{ Sl.No. } & \multicolumn{2}{|c|}{ Age Group } & \multicolumn{2}{|c|}{ Sex } & \multirow{2}{*}{ Total } & Percentage \\
\cline { 3 - 4 } & $60-69$ & Male & Female & & \\
\hline 01 & & 13 & 12 & 25 & 25.00 \\
\hline 02 & $70-79$ & 07 & 38 & 53 & 53.00 \\
\hline 03 & $80+$ & Total & $\mathbf{3 5}$ & $\mathbf{6 5}$ & 22 & 22.00 \\
\hline & & \multicolumn{2}{|c|}{} & $\mathbf{1 0 0}$ \\
\hline
\end{tabular}

The data in the above table clearly indicated that Majority of the Aged belonged to 70-79 groups (53.00 Percent). Table shows the gender with distribution of Elderly people in this study 35 is male elderly and 65 are females.

Table No. 02

Religious of the Respondents

\begin{tabular}{|c|c|c|c|c|c|}
\hline \multirow[b]{2}{*}{ Sl.No. } & \multirow{2}{*}{ Religion Group } & \multicolumn{2}{|c|}{ Sex } & \multirow[b]{2}{*}{ Total } & \multirow[b]{2}{*}{ Percentage } \\
\hline & & Male & Female & & \\
\hline 01 & Hindu & 20 & 54 & 74 & 74.00 \\
\hline 02 & Muslim & 10 & 08 & 18 & 18.00 \\
\hline 03 & Christian & 05 & 03 & 08 & 08.00 \\
\hline & Total & 35 & 65 & 100 & 100.00 \\
\hline
\end{tabular}

The Majority of Respondents in the present study (74.00 Percent) belonged to Hindu Persons in Arehalli Village.

Table No. 03

Caste Profile of the Respondents

\begin{tabular}{|c|l|c|c|c|c|}
\hline \multirow{2}{*}{ Sl.No. } & \multirow{2}{*}{ Caste Group } & \multicolumn{2}{c|}{ Sex } & \multirow{2}{*}{ Total } & Percentage \\
\cline { 3 - 6 } & & Male & Female & 45 & 45.00 \\
\hline 01 & SCs & 15 & 30 & 20 & 20.00 \\
\hline 02 & STs & 10 & 10 & 35 & 35.00 \\
\hline 03 & OBCs & 10 & 25 & $\mathbf{1 0 0}$ & $\mathbf{1 0 0 . 0 0}$ \\
\hline
\end{tabular}

Majority of the Elderly in the present study (45.00 Percent) belonged to SCs Classes.

Table No. 04

Type of Family of the Respondents

\begin{tabular}{|c|c|c|c|c|c|}
\hline \multirow[b]{2}{*}{ Sl.No. } & \multirow{2}{*}{ Type of Family } & \multicolumn{2}{|c|}{ Sex } & \multirow{2}{*}{ Total } & \multirow{2}{*}{ Percentage } \\
\hline & & Male & Female & & \\
\hline 01 & Joint Family & 25 & 50 & 75 & 75.00 \\
\hline \multirow[t]{2}{*}{02} & Nuclear Family & 10 & 15 & 25 & 25.00 \\
\hline & Total & 35 & 65 & 100 & 100.00 \\
\hline
\end{tabular}

Majority of the Respondents (75.00 Percent) of them belonged to Joint Family and Only (25.00 Percent) are Nuclear Family in Arehalli Village.

Table No. 05

Educational Background of the Respondents

\begin{tabular}{|c|l|c|c|c|c|}
\hline \multirow{2}{*}{ Sl.No. } & \multirow{2}{*}{ Educational Status } & \multicolumn{2}{|c|}{ Sex } & \multirow{2}{*}{ Total } & \multirow{2}{*}{ Percentage } \\
\cline { 3 - 6 } & & Male & Female & 53 & 53.00 \\
\hline 01 & Illiterate & 18 & 35 & 39 & 39.00 \\
\hline 02 & Primary Education & 12 & 27 & 08 & 08.00 \\
\hline 03 & Secondary Education & 05 & 03 & $\mathbf{1 0 0}$ & $\mathbf{1 0 0 . 0 0}$ \\
\hline
\end{tabular}

Table No. 05 out of 100 informants $53.00 \%$ are illiterate. It is painful to note that among the 65 Female informants as many as $53.00 \%$ are illiterate out of the total 39 informants who had studied up to primary school level, 12 are Men and only 27 are Women. Among the 08 who had Secondary level of Education 03 was Female and 05 are Men. This high percent illiteracy among the Female and fewer of them in other literate categories reveal the lessen importance given to education for women by the Society. 
Table No. 06

Marital Status of the Respondents

\begin{tabular}{|c|c|c|c|c|c|}
\hline \multirow[b]{2}{*}{ Sl.No. } & \multirow[b]{2}{*}{ Marital Status of the Aged } & \multicolumn{2}{|c|}{ Sex } & \multirow[b]{2}{*}{ Total } & \multirow[b]{2}{*}{ Percentage } \\
\hline & & Male & Female & & \\
\hline 01 & Unmarried & 01 & 02 & 03 & 03.00 \\
\hline 02 & Married & 18 & 13 & 31 & 31.00 \\
\hline 03 & Divorced & 02 & 01 & 03 & 03.00 \\
\hline 04 & Widowed & 10 & 47 & 57 & 57.00 \\
\hline 05 & Separated & 01 & 02 & 03 & 03.00 \\
\hline \multirow[t]{2}{*}{06} & Remarried & 03 & - & 03 & 03.00 \\
\hline & Total & 35 & 65 & 100 & 100.00 \\
\hline
\end{tabular}

A Study of the Marital Status of informants that too the aged, in the context of this study is important. Table No. 06 shows the marital status of our sampled informants. According to the table, 3 (1 and 2) are not Married at all in life, 31 (18 and 13) are Married, 3 (2 and 1) are Divorced, 57 (10 and 47) are Widowed, 3 (1 and 2) are Separated, and only Three male is Remarried.

Table No. 07

Morbidity observed in the study area $(\mathrm{N}=100)$

\begin{tabular}{|l|l|l|}
\hline SI.No. & Morbidity Condition of respondents & No. (\%) \\
\hline 01 & Joint Pains & $75(75.00)$ \\
\hline 02 & Chewing Problems & $70(70.00)$ \\
\hline 03 & Cataract & $55(55.00)$ \\
\hline 04 & Generalized body pain & $35(35.00)$ \\
\hline 05 & Hypertension & $40(40.00)$ \\
\hline 06 & Refractive error & $38(38.00)$ \\
\hline 07 & Impaired hearing & $27(27.00)$ \\
\hline 08 & Dermatological Complaints & $09(09.00)$ \\
\hline 09 & Chronic Cough & $05(05.00)$ \\
\hline 10 & Known Cardiac illness & $04(04.00)$ \\
\hline 11 & Known Diabetes & $10(10.00)$ \\
\hline 12 & Asthma & $05(05.00)$ \\
\hline 13 & Urinary Symptoms & $08(08.00)$ \\
\hline 14 & Gastrointestinal Pain & $14(14.00)$ \\
\hline 15 & Totally Blind & $02(02.00)$ \\
\hline
\end{tabular}

Table No. 07 the total number of illnesses among 100 subjects was 399 . Therefore, the average number of illnesses per persons was recorded as 2.45. As the table shows, complaints of joint pains $75.00 \%$ was the most common, followed by dental and chewing problems $70.00 \%$. Visual Problems due to Cataract and refractive errors were seen in 83.00 percent. Hypertension was found in 40.00 and Diabetes in 10.00 Percent. Gastrointestinal Pain in 14.00 Percent. Dermatological Complaints 09.00 Percent, heart illnesses 04.00 percent and Asthma in 08.00 Percent were less common.

Shows that all the respondents had health problems, the most common being hypertension, osteoarthritis, diabetes or bronchial asthma. Others included cataract, anemia, and skin problems. It is seen that most of the respondents had more than one health problem. Osteoarthritis was found to be more common among females while other health problems were almost similar among both the Genders. Most of the respondents had multiple problems.

\section{Findings:}

The problems of the aged vary from Society to Society and have many dimensions in our Country. Old age had never been problems for India where a value based Joint Family system is supposed to prevail. Indian culture is automatically respectful and supportive of elders. The main findings of the study are as follow;

1. The Majority of the respondents $(53.00 \%)$ belonged to the age groups of 70-79.

2. The Majority of respondents in the present study $(74.00 \%)$ belonged to Hindu Religious in Arehalli Village.

3. The Majority of the respondents $(75.00 \%)$ of the belonged to Joint Family.

4. The Majority of the respondents $(53.00 \%)$ were illiterates.

5. Elderly showed less health problems but they showed less psychological problems as compared to physical problems. 


\section{Summary and Conclusion:}

Generally the elderly people suffer from various diseases; such as blood pressures, diabetes, bronchitis, paralysis, arthritis, bone disorder, urination problems, reduced eyesight, diseases of skin and joints, nervous disorder, sleeplessness, loss of memory power etc., Among the 100 Respondents interviewed in the Survey, 35 Percent were Male and 65 Percent were Female. Majority of them were aged 70-79 Years, Majority of Elderly (53.00\%) were illiterates. Most of the Elderly (74.00\%) were Hindus. Majority of Elderly (75.00\%) were problems of Joint Pains. Majority of Elderly $(57.00 \%)$ were Widowed. About Majority of aged $(45.00 \%)$ belonged to other than SCs Group. More than of the elderly were Joint Family.

Almost all elderly had reported to have one or the other health problem. The overall Elderly Status of Elderly Significantly associated with education, marital status and family income. The health status of elderly assessed based on the self reported health problems revealed that poor vision/cataract/other eye impairment, arthritis/joint pain, back pain/high blood pressure, and etc., general condition were the major health problems of Elderly. Most of the health problems increased with the age of Elderly.

\section{References:}

[1]. Siva Raju S. (2002) "Health of the Elderly in India, issues and implications. Research and Development Journal.

[2]. Dhar H.L. (2005) Emerging geriatric Challenges.

[3]. Sathyanarayan R.T.S. and Shaji K.S. (25007) Demographic aging, Implications for mental health. 